\title{
Test Results from a Simulated High Voltage Lunar Power Transmission Line
}

\author{
Arthur Birchenough ${ }^{1}$, David Hervol ${ }^{2}$ \\ ${ }^{1}$ Power Systems Development Branch, Power and Avionics Division, \\ NASA Glenn Research Center, Cleveland, OH 44135 \\ ${ }^{2}$ Mechanical Systems Branch, Glenn Engineering and Scientific Support Organization, Analex Corporation, \\ NASA Glenn Research Center, Cleveland, $\mathrm{OH}$ \\ 216-433-9624, David.S.Hervol@nasa.gov
}

\begin{abstract}
The Alternator Test Unit (ATU) in the Lunar Power System Facility (LPSF) located at the NASA Glenn Research Center (GRC) in Cleveland, $\mathrm{OH}$ was modified to simulate high voltage transmission capability. The testbed simulated a $1 \mathrm{~km}$ transmission cable length from the ATU to the LPSF using resistors and inductors installed between the distribution transformers. Power factor correction circuitry was used to compensate for the reactance of the distribution system to improve the overall power factor. This test demonstrated that a permanent magnet alternator can successfully provide high frequency AC power to a lunar facility located at a distance.
\end{abstract}

Keywords: Energy conversion, High-current and high-voltage technology.

PACS: 84.60.- - h, 84.70.+p, 84.32.Ff, 84.32.Hh.

\section{INTRODUCTION}

A higher power electrical testbed was desired in order to evaluate the electrical control issues and system performance characteristics at representative conditions for Fission Surface Power Systems (FSPS) with multiple independently switched user loads. To meet these needs, the Lunar Power System Facility (LPSF) was developed and built. The LPSF contains an Alternator Test Unit (ATU), a Main Power Distribution Unit (MPDU), user loads, and an alternator controller using a Parasitic Load Resistor (PLR). In this form the LPSF was used to determine the alternator electrical performance, the effectiveness of the parasitic loading based speed and voltage controller, the power quality delivered to the loads, and system responses to transient loading conditions (Birchenough and Hervol, 2007). A fundamental requirement for unshielded or lightly shielded surface power is the ability to locate the fission power source at a distance from habitable areas. Transmission cables become a major source of weight and high voltage transmission lines are a way of dramatically reducing cable mass (Mason, 2006). As a result, the LPSF was modified to include a high voltage transmission simulator. The goal of this test was to demonstrate that the ATU could successfully deliver power to the end user loads with the addition of a high power transmission line simulator.

\section{LPSF DESCRIPTION}

The main elements of the LPSF are a $50 \mathrm{kWe}$ ATU, an alternator controller using a Parasitic Load Resistor (PLR), a Main Power Distribution Unit (MPDU), eight user loads and a high voltage transmission line simulator. These elements are made of breadboard/brassboard components. The LPSF configuration was developed using readily available off-the-shelf components and uses technologies that are applicable to FSPS. A block diagram of the test facility is shown in Figure 1. 


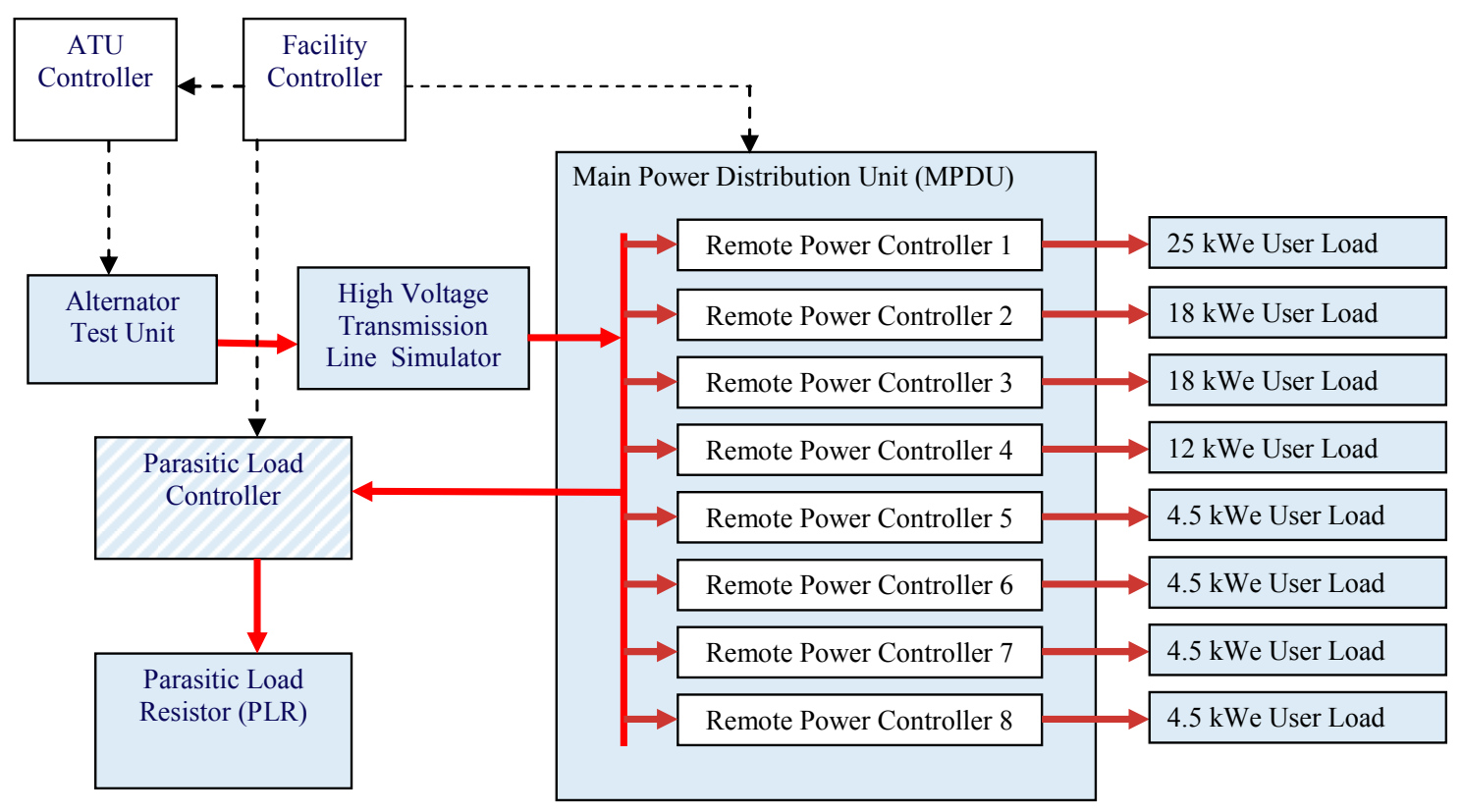

FIGURE 1. Overall Schematic of the Lunar Power System Facility (LPSF).

\section{Alternator Test Unit (ATU)}

The ATU is the power supply for the LPSF. It is representative of a style of alternator that would be used on a Brayton dynamic power conversion system. A variable speed 2-pole samarium cobalt permanent magnet brushless motor drives the alternator in place of a Brayton cycle power system. The alternator is a 6-pole permanent magnet alternator utilizing a Halbach array of samarium cobalt magnets. The stator has slots and is fabricated from hiperco 50 laminations that are skewed $1 / 2$ slot to minimize cogging and rotor can losses. The stator windings are paralleled small gauge copper strands to minimize high frequency losses. A dedicated control panel allows the motor to be operated in either speed or torque control. Speed control operation senses rotor speed and corrects any deviation by adjusting motor supply current. In torque mode a constant current is commanded for the motor, resulting in nearly constant torque output independent of the motor speed. A pressurized oil loop is included in the ATU assembly. Oil jets are used to lubricate and cool the individual shaft ball bearings and to cool the end turns of the motor and alternator. Additionally, oil passages are used to cool the rotor and stator. This waste heat is transferred through a commercial oil-to-water heat exchanger which is connected to the test facility water supply. The electronic motor drive controls are located in a separate cabinet on a cold plate which is also connected to the facility water supply. There is an emergency over speed shutdown circuit located within the ATU cabinet that trips if the shaft speed exceeds 40,000 rpm. ATU vibration health monitoring is performed with two sets of 3-axis accelerometers mounted on the alternator and motor housing exteriors. The ATU will automatically shutdown should any of the accelerometer readings exceed a predetermined g-level that would indicate an abnormal condition. The drive motor magnet health is monitored by periodically measuring back emf at shutdown and comparing it to beginning of life test values. The ATU is shown as installed in the LPSF at GRC in Figure 2. The oil-to-water heat exchanger, facility water pressure gauge, and oil pressure gauge are visible through the motor/alternator housing window.

\section{High Voltage Transmission Line Simulation}

A one kilometer length of high voltage transmission cable made up of AWG-14 wire with $1 / 8$ " line to line spacing was simulated by using a matching pair of three phase 12:1 ratio step-up/step-down transformers, with $4 \mathrm{ohm}$ resistors and $500 \mu \mathrm{H}$ inductors representing the resistive and inductive line losses. The high voltage transmission line simulator is shown in figure 3 . 


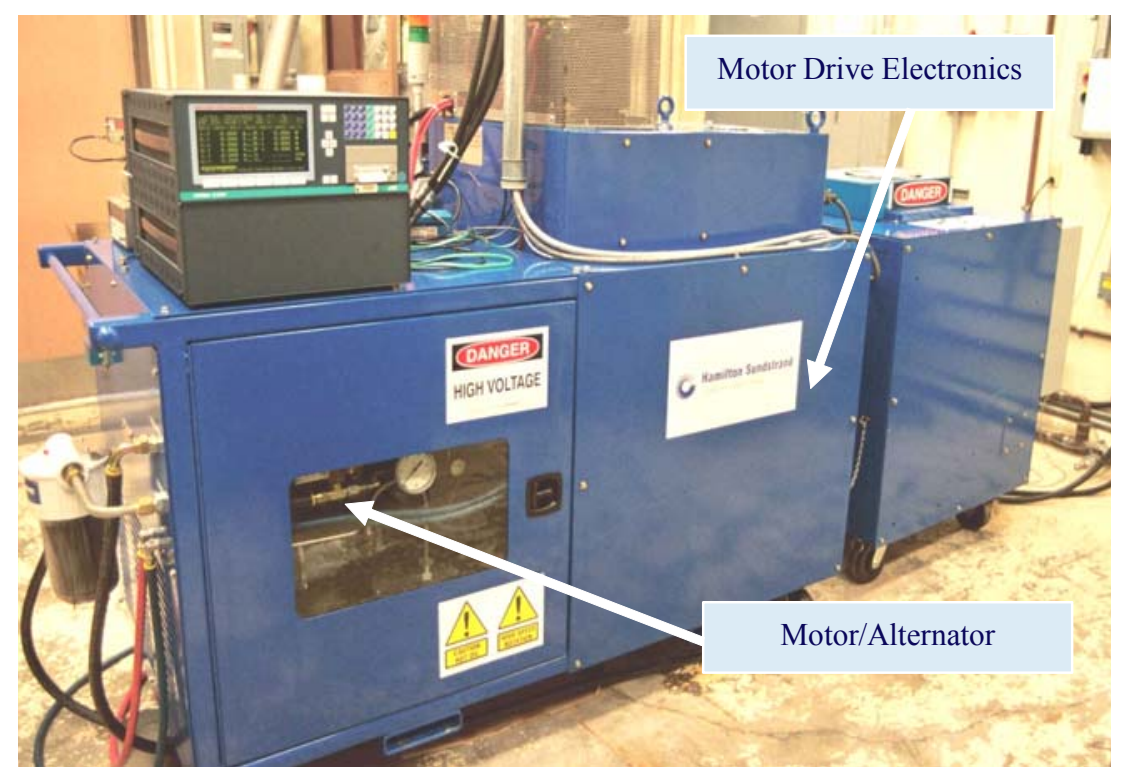

FIGURE 2. View of the ATU as Installed in the LPSF.

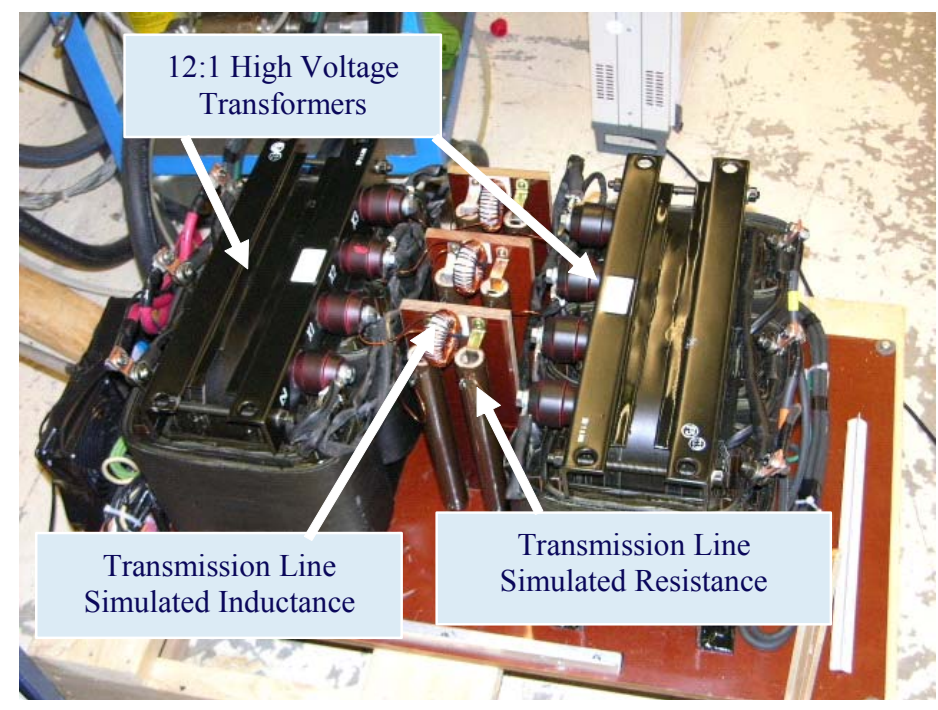

FIGURE 3. High Voltage Transmission Line Simulator.

The relative placement of the power factor correction circuitry is shown as a simplified schematic in figure.4 


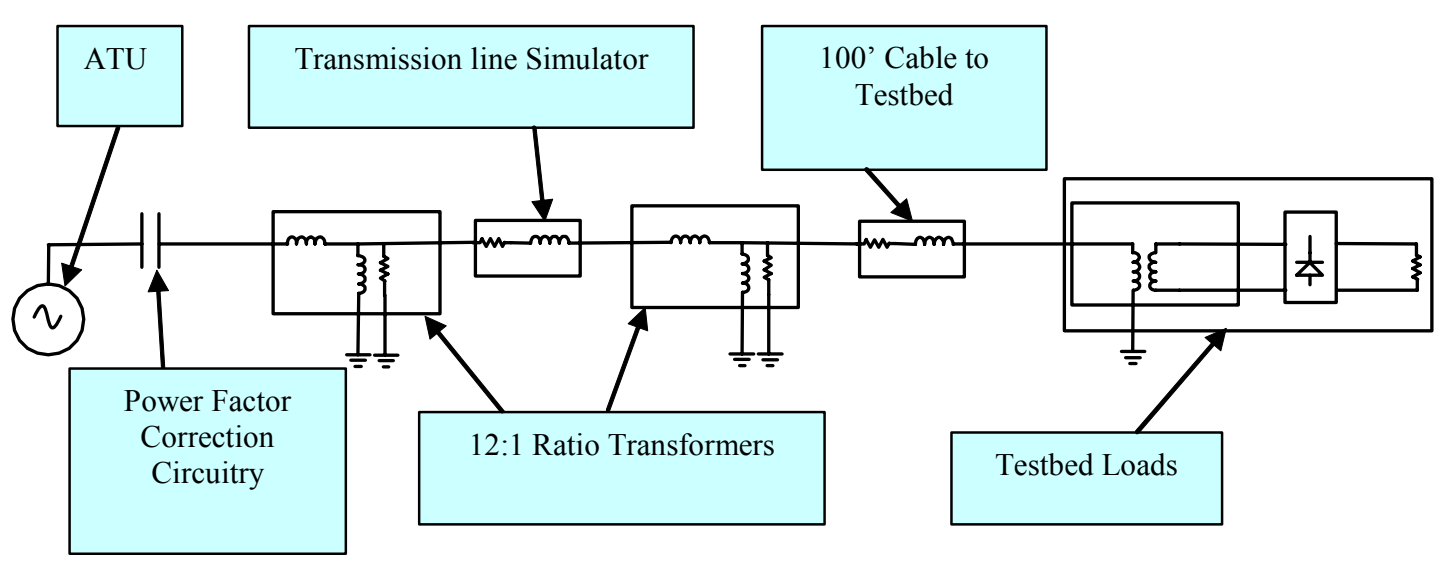

FIGURE 4. Relative Placement of Power Correction Circuitry.

\section{MPDU, Alternator Controller, PLR, and User Loads}

All of these components have been described in greater detail (Birchenough, Hervol, 2007). The MPDU contains the mechanical relays or contactors that distribute power from the ATU to the user loads and to the parasitic load resistor. The MPDU was sized to handle $50 \mathrm{~kW}$ at $400 \mathrm{VAC}$ line to line rms, 3 phase, $1750 \mathrm{~Hz}$ (corresponding to 35,000 rpm ATU shaft speed).

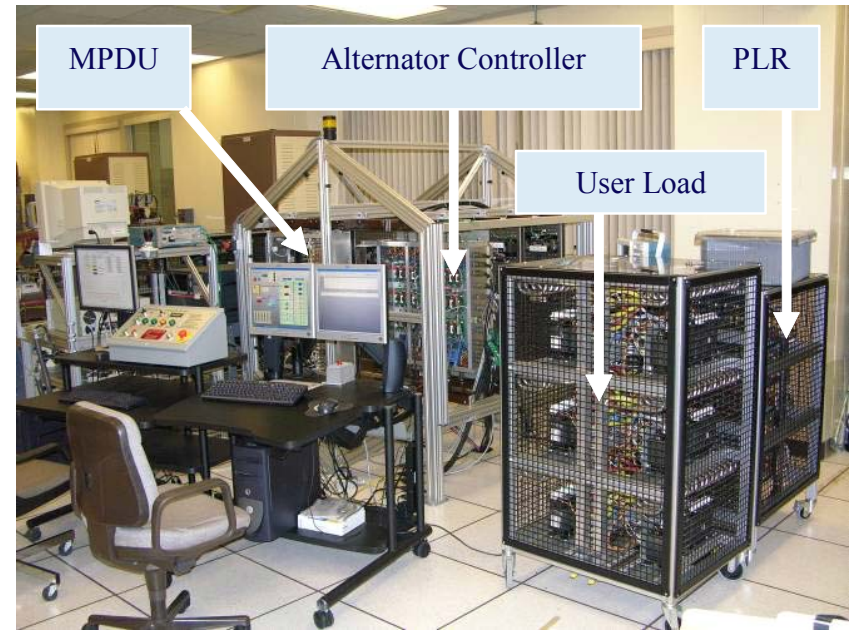

FIGURE 5. MPDU, Alternator Controller, PLR, and User loads as Installed in the LPSF.

The Alternator Controller and PLR maintain a nearly constant bus voltage and ATU shaft speed regardless of user loading. This is accomplished by applying a parasitic load to the alternator output to maintain total load as required for the desired output voltage and/or speed. This type of parasitic loading was also used very successfully on a 2 kW Brayton cycle power system (Hervol, Mason and Birchenough, 2003 and Birchenough, 2006). The User Loads are downstream of the high voltage transmission simulator, and are connected directly to the main distribution bus with a 400VAC line-to-line $3 \mathrm{Phase}, 1750 \mathrm{~Hz}$ feed. In order to process the AC power, each load implements a 3 Phase Transformer-Rectifier that changes the AC voltage level, rectifies, and then filters the AC into the required DC power. The MPDU, Alternator Controller, PLR, and User loads are shown in figure 5. 


\section{RESULTS AND DISCUSSION}

To determine baseline system performance values, the ATU was run without the high voltage transmission line simulator using the PLR to provide the electrical loading. The high voltage transmission line simulator was then installed and the system was retested in the same manner. Based on preliminary calculations, implementing high voltage transmission on a Brayton system high speed alternator was expected to be technically simple and straightforward, because the added losses of the transmission line were expected to be very low. The transmission line wire resistance was sized for a $1 \%$ power loss, and the inductive reactance was calculated to be $\sim 1 \%$ per unit impedance. These values would have resulted in a $1 \%$ reduction in power available to the loads if the source was still limited to $50 \mathrm{~kW}$, but the impedance would be low enough that only a $1-2 \%$ increase in alternator speed would be required to boost the source voltage enough to overcome the voltage drop in the high voltage line. However, it turned out that the losses in the step up and step down transformers were far more significant in determining how much power we could transmit. First, the magnetizing (no load) losses in the transformers were in the order of 1.2 kilowatts, greater than the expected full load transmission line losses. This was not unexpected, but the leakage inductance of the transformers, $\sim 35 \mu \mathrm{H}$ per transformer (referred to the primary), was 10 times the transmission line impedance, and the two transformer leakages are equal to $60 \%$ of the alternator inductance. This substantial increase in system impedance limited the system transmission power to between 30 and 35 kilowatts with a moderate $(\sim 10 \%)$ increase in the alternator speed.

The transformers used for the voltage step up and step down were not specifically designed for low leakage inductance, so an improved transformer design could probably have reduced the problem and allowed more power to be transmitted, but the leakage inductance was obviously an issue. A more elegant solution than simply optimizing the transformer design around that parameter, at the expense of mass or efficiency was desired. Series capacitors to cancel the inductive reactance were investigated. At normal power line frequencies, $60 \mathrm{~Hz}$, such capacitors would be prohibitively large; however at the $1750 \mathrm{~Hz}$ operating frequency of the Brayton high speed turbo alternator, the capacitor size was very modest. Consequently, the mass penalty for capacitor based reactance compensation is small. To that end, power correction factor circuitry was installed. The circuitry consisted of six (6) $30 \mu \mathrm{F}$ capacitors in parallel per phase. This allowed us to tailor the amount of corrective capacitance to optimize the power factor. This circuitry is shown in figure 6 . The relative physical locations of the high voltage transmission simulator and power correction circuitry are both shown in figure 7 .

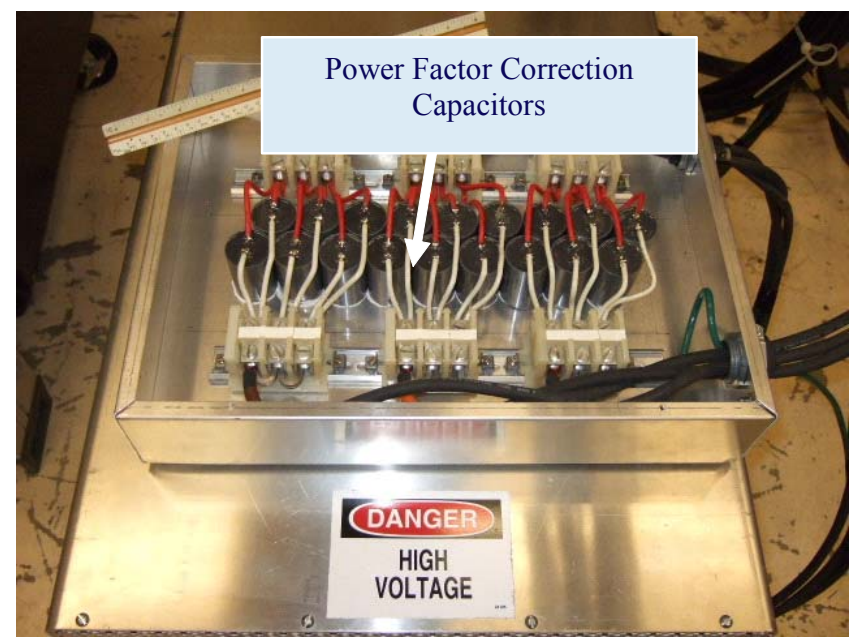

FIGURE 6. Power Factor Correction Circuitry. 


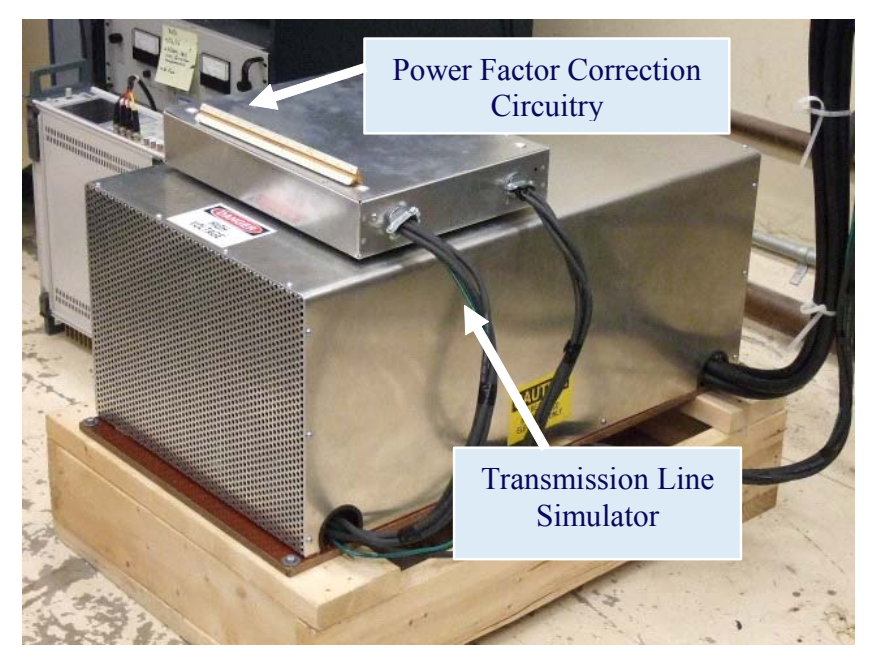

FIGURE 7. High Voltage Transmission Line Simulator and Power Correction Circuitry.

Several values of series capacitance were tried, and the power transmission capability increased consistently as we decreased the value of the capacitance to the value which was resonant with the transformer leakage inductance. At the resonant value the power transmission parameters were nearly identical to the values without the high voltage line simulation and transformers, other than the additional resistive power loss and the magnetizing power loss. The effects of the added inductance were successfully cancelled out. The results of ATU shaft speed as a function of ATU power is shown in figure 8. Three cases are shown: baseline, high voltage simulator without capacitors, and high voltage simulator with $90 \mu \mathrm{F}$ capacitive correction per phase.

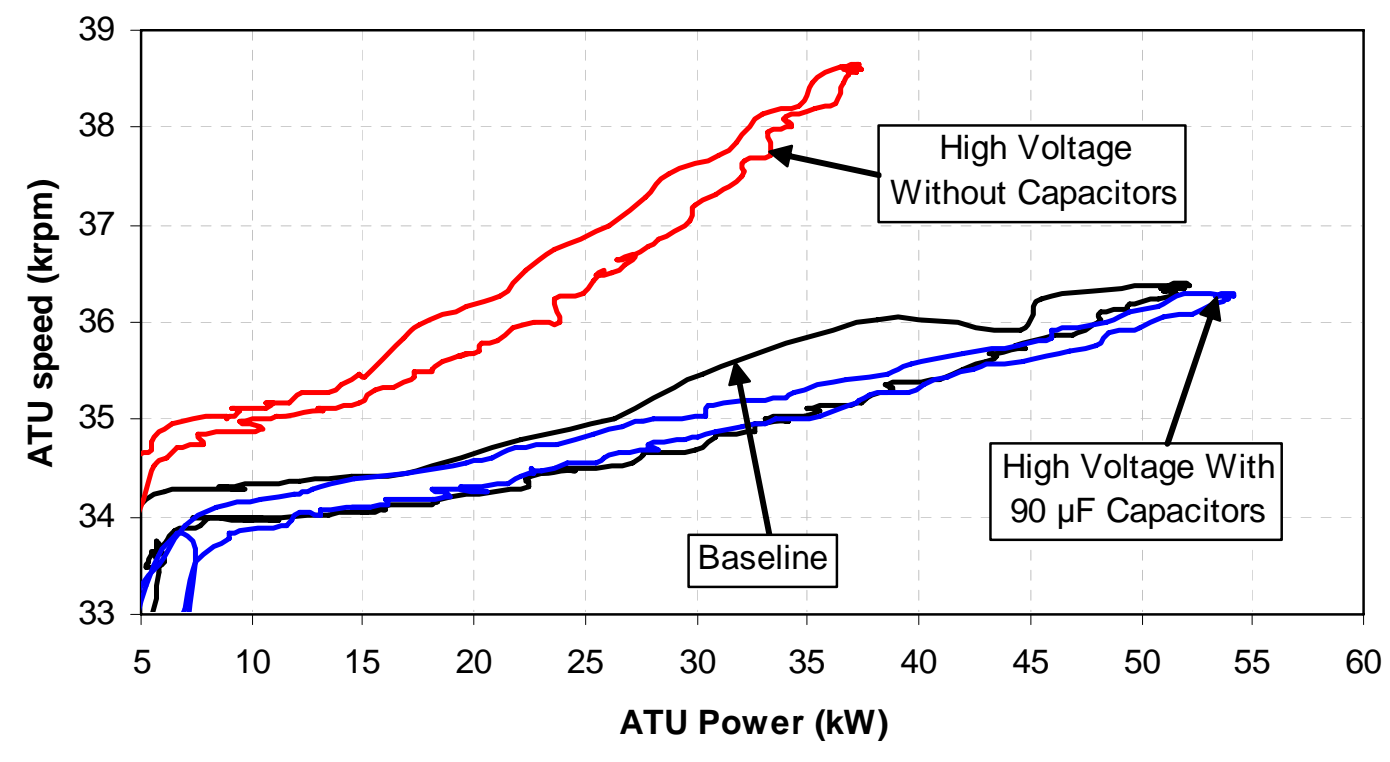

FIGURE 8. ATU Speed versus ATU Power.

It is clearly shown in figure 8 that $90 \mu \mathrm{F}$ of capacitance restored the ATU's ability to deliver full power at rotational speeds equal to or less than the baseline case. This correction capacitance improved the power factor to the ATU as shown in figure 9. 


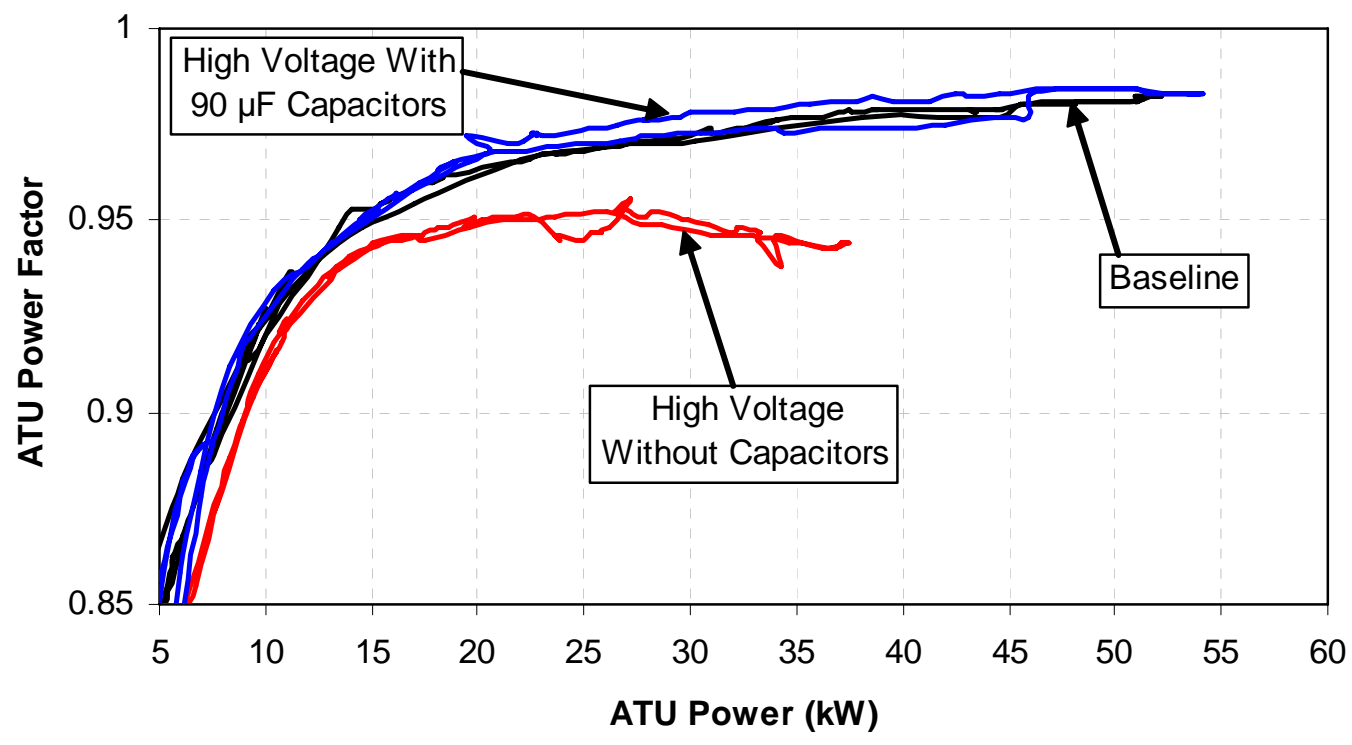

FIGURE 9. ATU Power Factor versus ATU Power.

The ATU voltage as a function of power level is shown in figure 10. The baseline data demonstrates that the ATU output voltage is essentially constant over a broad power band. The slope of the line is the voltage drop across the cable between the ATU and the MPDU. When the same test was run with the high voltage transformers and the transmission line simulation, but without the compensating capacitors, there was a substantial voltage drop at high power levels, due primarily to the high leakage inductance of the transformers.

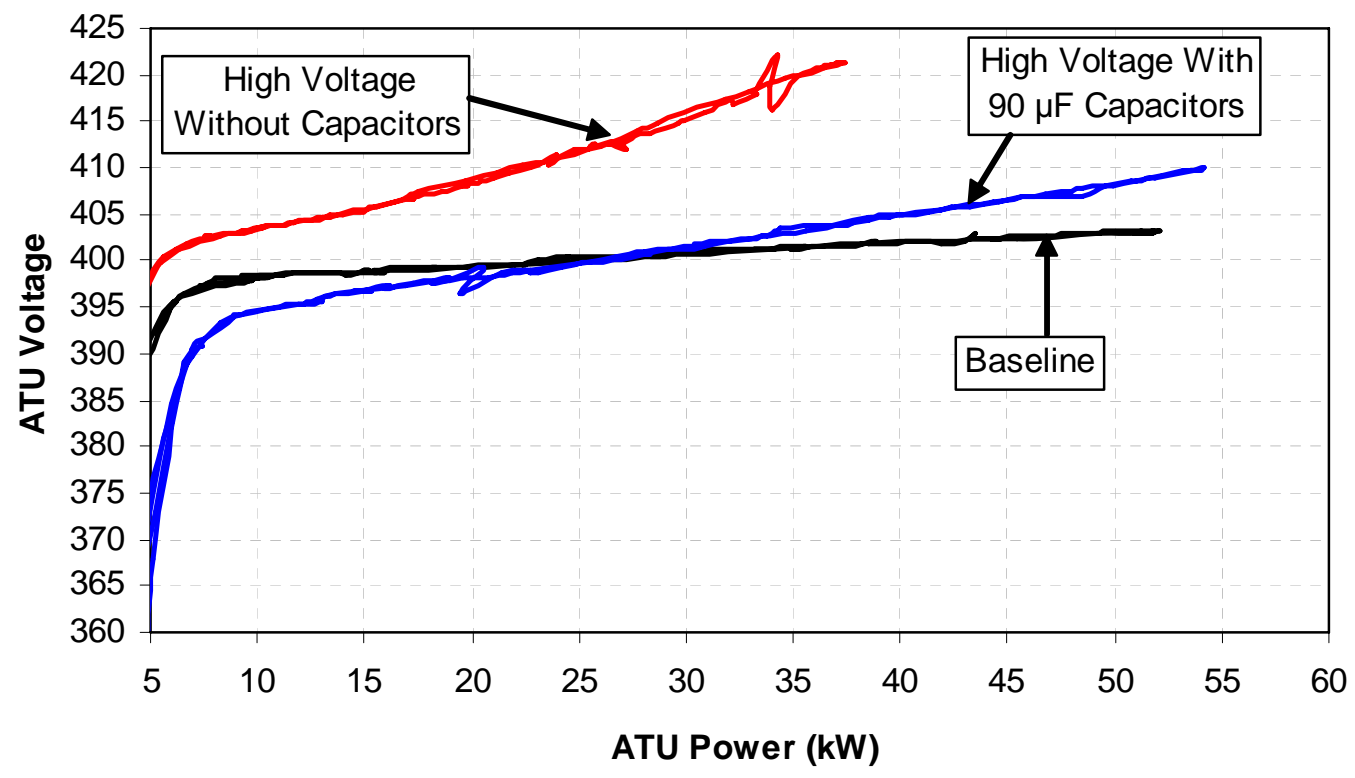

FIGURE 10. ATU Voltage versus ATU Power.

Once the capacitors were added to the circuit, the losses across the leakage inductance were largely cancelled. The remaining voltage drop corresponds to the IR losses in the transformers and the transmission line simulation. The MPDU bus distribution voltage was essentially unaffected in all three cases, as shown in Fig 11. 


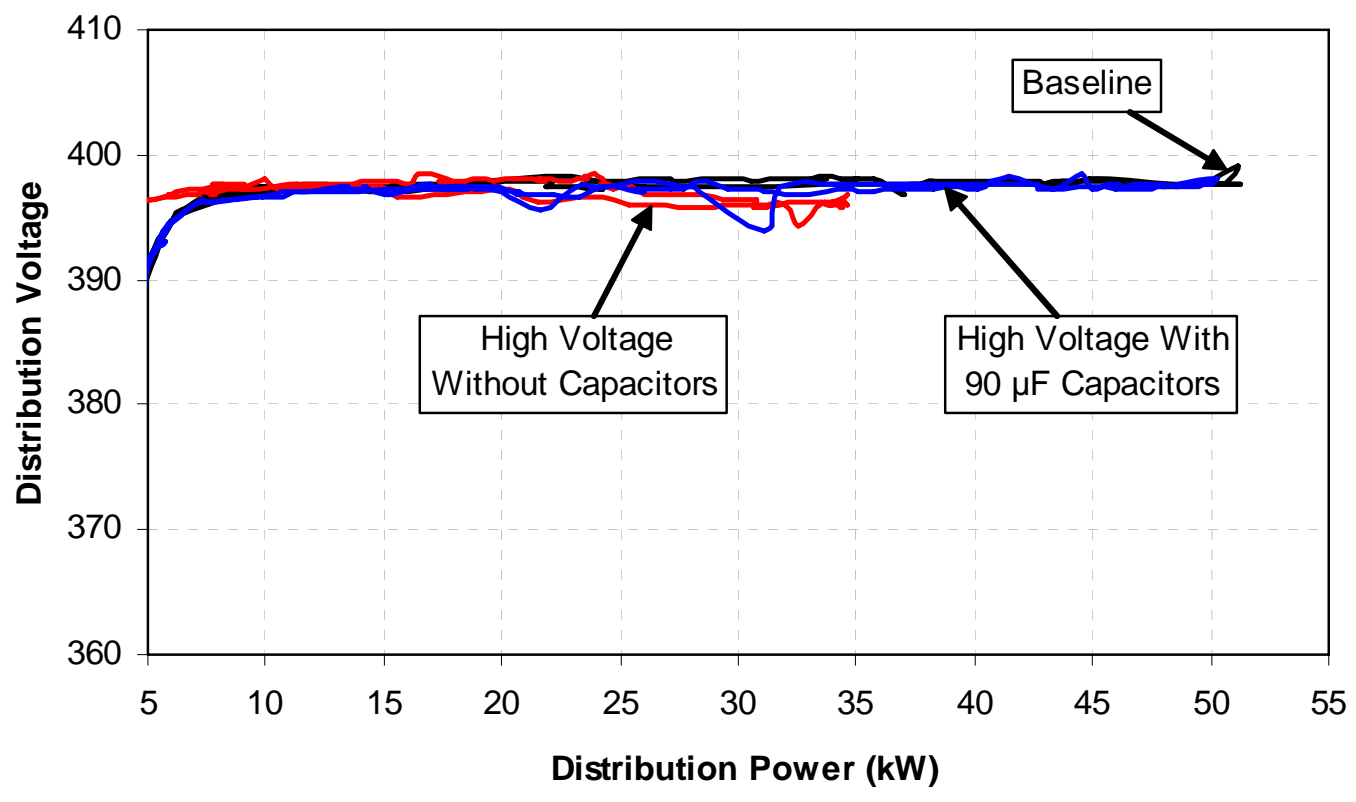

FIGURE 11. Distribution (MPDU) Voltage versus ATU Power.

\section{CONCLUSIONS}

These tests demonstrate the practicality of high voltage and high frequency AC electrical power transmission generated by a permanent magnet alternator compatible with a Brayton cycle engine. High frequency power systems such as this one are likely to experience inductive reactance due to restraints in alternator windings, transmission lines, step-up and step-down transformers, and distribution transformers. For example, these tests revealed a reduced power delivery capability when the high voltage transmission simulator was first installed. However, this was easily corrected through the use of series capacitors. Specifically, the data showed that the baseline distribution bus power output of $50 \mathrm{kWe}$ was initially limited by the transmission simulator to $35 \mathrm{kWe}$. By adding $90 \mu \mathrm{F}$ of capacitance per phase, the distribution bus power was restored to $50 \mathrm{kWe}$. The amount of reactance capacitance is only $3-4 \%$ of the value required at $60 \mathrm{~Hz}$ to provide the same effect. Adding series capacitance should be an effective tool to overcome the effects of inductance in the transmission system, or even tune the alternator impedance to control fault currents and system impedances.

\section{NOMENCLATURE}

$\mu \mathrm{H} \quad=$ microhenrys, unit of electrical inductance

$\mu \mathrm{F} \quad=$ microfarad, unit of electrical capacitance

$\mathrm{Hz} \quad=$ Hertz, cycles per second

$\mathrm{krpm}=$ thousand revolutions per minute

emf $=$ electromotive force

\section{ACKNOWLEDGMENTS}

The work in this paper was performed for NASA Exploration Systems Mission Directorate and the Prometheus Power and Propulsion Program. The authors would like to thank Vicki Crable, Don Fong, Marcelo Gonzalez, Larry Trase, Mike Chornak, Kevin Blake, Dave Hausser, and Tom Balogas for their assistance with testing. The opinions expressed in this paper are those of the authors and do not necessarily reflect the views of the National Aeronautics and Space Administration. 


\section{REFERENCES}

Birchenough, A., "The 2kW Mini-BRU Electrical Controls Concept and Transient Performance," NASA/TM-2006-214043, NASA GRC, Cleveland, OH, 2006.

Birchenough, A., and Hervol, D.S.," Experimental Operational Results from a High Power Alternator Test Bed," in proceedings of Space Technology and Applications International Forum (STAIF-2007), edited by M. S. El-Genk, AIP Conference Proceedings 880, Melville, NY, 2007, pp. 692-699.

Hervol, D.S., Mason, L.S., and Birchenough, A.," Experimental Results from a $2 \mathrm{~kW}$ Brayton Power Conversion Unit," in proceedings of Space Technology and Applications International Forum (STAIF-2003), edited by M. S. El-Genk, AIP Conference Proceedings 665, Melville, NY, 2003, pp. 621-628.

Mason, L., "A Comparison of Fission Power System Options for Lunar and Mars Surface Applications," NASA/TM-2006214120, NASA GRC, Cleveland, OH, 2006. 